\title{
A Humanização no Ensino de Graduação em Medicina: o Olhar dos Estudantes
}

\section{Humanization in Undergraduate Medical Training: the Students' Point of View}

Izabel Cristina Rios ${ }^{I}$ Caroline Braga Sirino

\section{PALAVRAS-CHAVE}

- Humanização da Assistência;

- Educação Médica;

- Ensino;

- Humanidades.

\section{KEYWORDS}

- Humanized Care;

- Medical Education;

- Teaching;

- Humanities.
Recebido em: 20/01/2015

Aprovado em: 13/05/2015

REVISTA BRASILEIRA DE EDUCAÇÃO MÉDICA
${ }^{2}$ Universidade de São Paulo, São Paulo, SP, Brasil.

"I Universidade Presbiteriana Mackenzie; Universidade de São Paulo, São Paulo, SP; Brasil. 


\section{INTRODUÇÃO}

A "humanização", atualmente, é um tema recorrente nos serviços de saúde. Muito utilizado e de caráter polissêmico, o termo "humanização" se refere a movimentos, conceitos, ações de diferentes origens históricas e linhas de pensamento, dando margem a várias interpretações ${ }^{1,2}$. Nas palavras de Benevides e Passos ${ }^{3}$ : “A luta pela humanização das práticas de saúde já estava colocada em pauta no movimento feminista na década de 1960, ganhando expressão no debate em torno da saúde da mulher" (p. 390). Mas é marcadamente a partir do final da década de 1980 que a humanização se propaga como um movimento técnico-político na área da saúde ${ }^{4,5,6}$, ganhando cada vez mais espaço nas discussões em torno da qualidade dos serviços de saúde. Nos anos 2000, a humanização passa a compor políticas públicas do SUS, destacando-se a Política Nacional de Humanização do Ministério da Saúde (PNH).

$\mathrm{Na} \mathrm{PNH}$, destaca-se como um dos pontos capitais da humanização a oposição à violência gerada por "maus-tratos" físicos, psicológicos e simbólicos ${ }^{7}$. Outro ponto foca a melhoria na qualidade dos serviços prestados, articulando os avanços tecnológicos com o bom relacionamento, traduzindo a humanização como proposta de oferecer atendimento de qualidade técnica, ética e relacional. Nesse sentido, a relação médico-paciente é elemento-chave na atenção à saúde, incluindo aspectos referentes à subjetivação da assistência e o direito à informação ${ }^{8}$.

A humanização também é vista como ampliação do processo comunicacional, apoiada no diálogo. Para Ayres ${ }^{9}$, é no estabelecimento de interações apoiadas na intersubjetividade, ou seja, na capacidade de criação de um campo de compreensão aprofundada do outro pela linguagem que o cuidado poderá se realizar na perspectiva da humanização.

No campo do ensino médico, $\operatorname{Rios}^{10}$ aponta um paradoxo: embora reconhecida a importância e atualidade do tema no campo da saúde, há grande dificuldade de integração dos temas humanísticos ao corpo da medicina. Apesar de essencial à prática médica, a humanização ainda é vista como um tema desinteressante e descartável.

Pereira e Almeida ${ }^{11}$ atribuem tais dificuldades à visão fragmentada do ser humano nas práticas educativas na área da saúde. Afirmam haver três momentos que marcam a educação médica na América Latina. O primeiro em 1960, quando da atenção maior ao aspecto quantitativo, voltado ao aumento do número de alunos de Medicina, justificado pela carência de médicos. Nesse período, a ênfase recai sobre número de escolas, proporção professor-aluno, cargas horárias curriculares e disciplinares, número de leitos hospitalares por aluno, número de alunos por cadáver ou por microscópio, entre outros, ou seja, as mudanças na educação se concentraram nas relações técnicas entre os agentes e o processo de ensino.

O segundo momento entre 1970 e 1980, quando o foco se deu na dimensão qualitativa da educação, levantando questões referentes às ações pedagógicas e organizacionais no âmbito universitário, voltadas ao aprendizado prático nos serviços hospitalares e ambulatoriais.

$\mathrm{O}$ terceiro momento se refere à relevância do conceito de qualidade no centro desta discussão. Nesse momento, iniciam-se mudanças na formação de médicos, dando especial atenção ao sentido social da produção do conhecimento e à diversidade de paradigmas no campo da saúde. O possível caminho metodológico para uma educação médica seria voltar seu olhar para o homem na sua globalidade, rompendo com estruturas conservadoras, autoritárias e mercadológicas da formação médica, abrindo espaço para uma formação baseada na integração entre ciências e humanidades.

Nessa linha de pensamento, segundo as Diretrizes Curriculares Nacionais do Curso de Graduação em Medicina ${ }^{12}$, art. $3^{\circ}$, o médico formado deve ter o seguinte perfil:

\section{[...] formação generalista, humanista, crítica e reflexiva, ca- pacitado a atuar, pautado em princípios éticos, no processo de saúde-doença em seus diferentes níveis de atenção, com ações de promoção, prevenção, recuperação e reabilitação à saúde, na perspectiva da integralidade da assistência, com senso de responsabilidade social e compromisso com a cidadania, como promotor da saúde integral do ser humano. (p. 1)}

$\mathrm{O}$ artigo $6^{\circ}$, parágrafo IV, também assegura na formação médica a "compreensão e domínio da propedêutica médica - capacidade de realizar história clínica, exame físico, conhecimento fisiopatológico dos sinais e sintomas; capacidade reflexiva e compreensão ética, psicológica, humanística da relação médico-paciente."12 (p. 3). Assim como o art. 12, parágrafo III, integra "aspectos humanísticos e éticos para o desenvolvimento de atitudes e valores do aluno"12 (p.5).

Apesar do movimento para a inserção de temas da humanização na formação de profissionais na área da saúde, sua realização ainda apresenta grandes obstáculos no ensino médico.

Há algum tempo, disciplinas de humanidades estão sendo incluídas nos currículos médicos de faculdades de diversos países ${ }^{10}$. Entretanto, sua integração às demais disciplinas curriculares ainda é problemática. Assim como nos hospitais, a formação médica tende a ser mais voltada a aspectos biomédicos, reduzindo as propostas de humanização das práticas de saúde de ensino a ações de amenização de tensões cotidianas na área da saúde. 
Na Faculdade de Medicina da Universidade de São Paulo (FMUSP), desde 1998, introduziram-se disciplinas de humanidades na grade curricular. Tais disciplinas cobrem temas referentes a aspectos éticos, filosóficos, históricos, antropológicos, psicológicos, políticos, sociais e bioéticos da prática médica, sem, contudo, conseguir uma efetiva integração curricular com o núcleo duro, e fortemente tecnicista, da graduação ${ }^{10}$. Por outro lado, um levantamento realizado por esta autora em 2010 mostrou que, das 122 disciplinas curriculares (exceto as de humanidades), 81 afirmavam desenvolver temas humanísticos em suas atividades educacionais, apontando o fato de que a inserção curricular das humanidades não é mais questionada, restando conhecer como e onde ela ocorre, ou o contrário, e por quê.

Tal contexto justifica e realça a necessidade do desenvolvimento de pesquisas educacionais que permitam maior alcance na compreensão de como e onde se aprende a humanização ou seu contrário, assim como o embasamento de ações relacionadas à humanização no ensino na área da saúde.

Neste estudo, buscou-se identificar percepções dos alunos da graduação em Medicina acerca da humanização das práticas de saúde nos ambientes de ensino, assim como promover sua reflexão sobre a mesma. A investigação desse tema com base no que os alunos falam de suas vivências, concepções e impressões sobre a humanização na graduação poderá subsidiar a construção de estratégias de ensino-aprendizagem para a integração das humanidades na prática médica, assim como aprimorar a compreensão e a realização da humanização nas práticas de saúde.

\section{METODOLOGIA}

Neste estudo, adotamos como técnica de investigação do campo experiencial entrevistas semiestruturadas, pela possibilidade de obter relatos vividos e aprofundados sobre o tema.

As questões que serviram como base orientadora para as entrevistas foram: Para você, o que é humanização? Conte sobre uma situação de falta de humanização que você viveu ou vive durante a graduação em Medicina. Conte sobre uma situação de humanização que você viveu ou vive durante a graduação em Medicina. Em sua opinião, o que tornaria o ensino médico mais humanizado?

Os sujeitos deste estudo foram alunos de Medicina, de ambos os sexos, que estavam no sexto ano da graduação. Optamos pelo sexto ano porque assim os alunos já teriam tido vivências suficientes nos cenários tanto de ensino teórico quanto de ensino prático para que pudessem relatar suas impressões sobre o tema em estudo. Além disso, o internato corresponde ao período de maior proximidade do ensino do ato médico e da construção da identidade profissional e seu modo de atuar. Durante o internato, os alunos se reúnem em pequenos grupos distribuídos por afinidade, denominados "panelas" (grupos de alunos que passam pelos diversos setores e disciplinas durante o internato ou estágios de prática no quinto e sexto ano da graduação médica). Cada panela possui um representante perante a comissão de graduação, que é escolhido pelo próprio grupo. Assim, a amostra estudada não se refere a uma amostra representativa, mas a alunos considerados informantes-chave.

Em 2010, convidamos a participar da pesquisa um estudante de cada uma das 12 panelas. Foram marcados encontros no Centro de Desenvolvimento da Educação Médica (Cedem) da Faculdade de Medicina da Universidade de São Paulo para realização das entrevistas pela pesquisadora de campo, em sessões individuais que foram gravadas, totalizando 12 entrevistas, com cerca de 40 minutos cada uma, transcritas por terceiros e conferidas.

Como método de análise do material das entrevistas, adotamos a perspectiva hermenêutica ${ }^{13,14}$, segundo a qual construímos unidades de significado com base nos discursos dos sujeitos. Assim, a criação das categorias empíricas e analíticas foi realizada após um detalhado processo de análise do material coletado.

\section{RESULTADOS}

As categorias analíticas que emergiram e foram identificadas nos discursos dos alunos contemplaram diversos aspectos da relação entre o tema humanização e os estudantes de Medicina entrevistados. A seguir, estes aspectos serão descritos de acordo com sua categoria analítica.

\section{Conceito de humanização}

O conceito carrega sua importância por ser mais do que apenas uma palavra ou expressão, mas, sim, um sentido acompanhado de história e representações do objeto a que se refere ${ }^{15}$. O conceito de humanização é, assim, elemento básico para a compreensão do sentido da humanização e o que ela representa para os alunos de Medicina.

Neste estudo, adotamos determinados conceitos de humanização, em relação aos quais interpretamos as concepções trazidas pelos alunos. Com a definição a seguir, de Rios ${ }^{4}$, procuramos tomar como referência um amplo alcance de sentido de humanização:

A humanização pode ser compreendida como princípio de conduta de base humanista e ética, como movimento contra violência institucional na área da saúde, como política públi- 
ca para atenção e gestão no SUS, como metodologia auxiliar para gestão participativa e por fim como tecnologia do cuidado na assistência à saúde. Busca a transformação da cultura institucional, através de compromisso ético e metodologias para ação dentro da saúde. (p. 10)

Numa linha semelhante de referenciamento, de acordo com a Cartilha da $\mathrm{PNH}^{7}$, entende-se por humanização:

a valorização dos diferentes sujeitos implicados no processo de produção de saúde: usuários, trabalhadores e gestores. Os valores que norteiam essa política são a autonomia e o protagonismo dos sujeitos, a corresponsabilidade entre eles, o estabelecimento de vínculos solidários, a construção de redes de cooperação e a participação coletiva no processo de gestão. (p. 4)

A definição do conceito de humanização para os alunos entrevistados apresenta elementos de imprecisão e insegurança ao afirmarem algo sobre este tema. Esta característica esteve presente em todos os entrevistados, nuns mais, e noutros menos. Contudo, é possível identificar na fala dos alunos características da humanização contidas nas referências adotadas neste estudo. Definição de humanização para o aluno 8:

"[...] Pela palavra, humanização é o processo de se tornar alguma coisa humana, mas a questão é o que é tornar alguma coisa humana... não é uma coisa tão simples de se responder. Eu acho que... na medicina, seria de repente tentar, ao máximo, transpor aquela barreira que existe entre o que é o médico, o que é o paciente, pensar que são duas pessoas se relacionando de alguma forma ali e tentar ver quais são os fatores que podem atrapalhar esse tipo de relacionamento e quais são os que podem ajudar. E dessa forma tentar encontrar uma forma de tornar esse relacionamento mais humano". (aluno 8)

O aluno 8 fala sobre a relação que se faz do termo humanização com a ideia de tornar humano e ao mesmo tempo problematiza essa relação ao perguntar o que é tornar algo humano e a complexidade de abordar esta questão. Nesse pensar, aproxima-se da proposta de construção de protagonismo dos sujeitos médico e paciente, como diz a PNH. Também se aproxima da humanização como busca de incluir valores humanísticos nas relações ${ }^{4}$.

Expressões como "pergunta difícil", "pergunta complexa" ou "como vou responder?" traduzem um pouco a imprecisão e a pouca familiaridade dos alunos com o tema; alguns até demonstraram grande dificuldade em organizar ideias em torno de uma definição. Porém, ao fim das entrevistas, frequentemente chegavam a uma ideia de humanização contendo características próximas às referências adotadas - por exemplo: características concernentes a empatia, aspectos éticos, relações humanas, respeito e responsabilidade.

A ideia do cuidado em saúde também foi frequentemente relacionada com o conceito de humanização. A seguir, o aluno 5 cita o exemplo de um professor que lhe proporcionou uma reflexão sobre o sentido terapêutico no atendimento, numa linha que se aproxima do cuidado enquanto prática que requer a abordagem das necessidades e expectativas existenciais mais amplas acerca da saúde/adoecimento ${ }^{9}$. No exemplo, o médico e professor buscou a compreensão do paciente e possíveis mudanças efetivas na vida deste para a sua melhora:

"[...] aprendi muito com a demonstração de um professor que tomou conta de um problema pessoal do paciente, que foi atrás de encaminhar o paciente para o lugar correto, que soube orientar o paciente na parte de mudança de estilo de vida e outras coisas, que eu acho que são importantes para a humanização do tratamento, e não somente prescrever um remédio, mandar tomar e voltar se tiver algum problema. [...] Isso mudou o meu ensino, eu acho, me fez ser alguém mais ligado a essa parte extra do paciente, a gente chama de extra porque a gente é focado... como eu falei, em reconhecer padrões, tratar padrões, tratar com tal remédio, por tanto tempo e pronto..." (aluno 5)

Na reflexão do aluno, a atenção "extra" oferecida ao paciente vai além dos protocolos biomédicos. Ainda que indiretamente, o aluno se aproxima da ideia de cuidado na relação médico-paciente na perspectiva de Ayres, segundo a qual, o pensar em saúde, a reflexão e a ressignificação da existência do ser e construções sociais são importantes para uma ação efetiva em saúde. Para esse autor, trata-se de recuperar a dimensão da saúde no que ele chama de projeto de felicidade - o conjunto de representações, desejos, expectativas e elementos da subjetividade capazes de mover as pessoas na construção de sua saúde, uma vez que dá sentido ao que é vivido e para o que se irá viver relacionado à saúde ${ }^{9}$.

\section{Interatividade}

No contexto deste trabalho, entendemos por interatividade "a realidade compartilhada que envolve a atenção conjunta a objetos de referência e a comunicação dentro de um domínio linguístico comum"16 (p.184). Nesta categoria, buscou-se compreender como as relações referentes às questões abordadas pela humanização acontecem, sob a ótica dos estudantes. Dois 
aspectos foram mais destacados por eles: a relação médico-paciente e a empatia como habilidade comunicacional.

Com base nas experiências e opiniões de cada aluno entrevistado, podem-se visualizar elementos da intersubjetividade que fazem parte da atenção à saúde e do ensino médico. Tais interações se referem a pacientes, professores, faculdade e entre eles mesmos, destacando-se a relação médico-paciente.

A comunicação e a compreensão entre médico e paciente podem aproximar esses dois lados da relação, sendo que a familiaridade, a confiança e a colaboração são parte de um processo diagnóstico e terapêutico ${ }^{8}$.

Percebe-se, pelas falas dos alunos, que a definição conceitual desta relação não é muito clara, porém os estudantes destacam sua importância e elementos presentes nela de forma mais intuitiva e repetitiva em seus discursos.

O aluno 9 comenta que o desenvolvimento da relação médico-paciente não se dá da mesma forma como se aprende fisiologia, por exemplo. De fato, isso não aponta simplesmente o evidente, por se tratar de duas áreas distintas, mas enfatiza a necessidade de repensar e refletir sobre como estas áreas estão sendo transmitidas. Também aponta que cada encontro levará a uma relação diferente.

"[...] muitas vezes, você vai, senta e fica assistindo a uma aula sobre relação médico-paciente. E relação médico-paciente não é algo que surge de conceitos que se deem em uma aula. Então... teria que pensar outra estratégia individual. Cada pessoa, cada médico, estudante, cada paciente tem a sua versão das coisas. Então, cada relação é uma relação diferente. É difícil você ensinar esse tipo de matéria desse jeito, porque é muito mais do que isso... você não tem uma padronização. Mas não dá para você ensinar como você ensina, por exemplo, fisiologia, sentada na cadeira ensinando, não tem como". (aluno 9)

O aluno chama a atenção para o fato de que o ensino de temas referentes à subjetividade das pessoas, que em nossas referências é o fulcro da humanização, necessita de métodos didático-pedagógicos diferentes do modelo tradicional de ensino por transmissão de conteúdos teóricos. Esta observação vem ao encontro de estudos sobre a formação humanística em Medicina $^{17}$.

Ao retomar a ideia de que a relação médico-paciente é um elemento-chave na atenção à saúde ${ }^{8}$, a humanização seria um elemento da qualidade relacional, porque propõe um processo comunicacional apoiado no diálogo. Nesse aspecto comunicacional, a aproximação com a humanização, nas falas dos alunos, surge ligada à ideia de empatia, como discutiremos a seguir.
A empatia é a característica mais presente no discurso dos alunos, tanto para a definição da humanização, quanto no que diz respeito à qualidade da relação médico-paciente. Tais concepções se aproximam dos nossos referenciais, nos quais a empatia é um constructo multidimensional (nas esferas cognitiva, comportamental e afetiva), que atua como recurso para a regulação da vida social, modificado pela cultura e pelo aprendizado $^{18}$.

A perspectiva dos alunos reflete também a importância da comunicação e da compreensão para a qualidade do atendimento apontada na literatura ${ }^{19}$. Estudos revelam que habilidades comunicacionais afetam de forma significativa o cuidado em saúde, melhorando a qualidade no atendimento. Como se trata de habilidades que podem ser ensinadas e aprendidas ${ }^{19}$, preconiza-se seu desenvolvimento nas escolas médicas ${ }^{20}$

Entretanto, para além dos protocolos básicos de habilidades comunicacionais, as relações interpessoais são complexas e precisam ser consideradas dentro de uma compreensão das subjetividades envolvidas. Segundo $\operatorname{Rios}^{4}$, os aspectos que dizem respeito às subjetividades "se constituem da interação entre o mundo interno (incluindo a biologia) e a história, valores e lugares da cultura da época, presentes desde antes do nascimento, a começar pela própria família que preparou o berço" (p. 42). Para a autora, é do campo da intersubjetividade que emerge a melhor compreensão dos problemas e a busca de soluções compartilhadas.

Atualmente, empatia pode ser compreendida por diferentes linhas conceituais. Enquanto habilidade comunicacional que envolve as subjetividades, a empatia apresenta componentes cognitivos, afetivos e comportamentais, que sinergicamente buscam a compreensão acurada das necessidades e perspectivas do outro. Por esse referencial teórico, faz parte da habilidade empática conseguir também expressar essa compreensão de forma que o outro perceba isto, ou seja, é também a capacidade de comunicar a compreensão que se tem do outro, sem necessariamente experimentar o seu sentimento ${ }^{21,18}$. A fala do aluno 12 se aproxima desse conceito:

\footnotetext{
"[...] acho que a partir do momento em que você compreende o que a outra pessoa está passando, eu acho que aí você toma atitudes que são humanizadas no sentido de respeitar o que a pessoa está passando e de trazer para ela uma conduta ou uma ação que seja pertinente para aquilo que ele está passando naquele momento". (aluno 12)
}

A importância que os alunos depositam nessa habilidade é muito grande. No entanto, essa definição aparece de forma 
intuitiva e não como algo compreendido como parte integrante do conteúdo do ensino médico, tanto que o mesmo aluno relata que a empatia é exclusivamente um valor humano, algo pessoal e particular, não necessariamente adequado ao campo profissional.

\footnotetext{
"Acho que empatizar em si é uma coisa meio pessoal... não é uma coisa profissional, é uma coisa de humano para humano. Não de profissional para paciente ou para cliente ou o que seja..."(aluno 12)
}

\section{Gestão dos serviços de saúde}

Embora o foco deste trabalho não se atenha ao tema "gestão" e seus desdobramentos, é importante ressaltar que este termo é cada vez mais usado no âmbito da humanização, esta compreendida inclusive como uma ferramenta de gestão para a qualidade do atendimento, a integralidade e a qualidade profissional ${ }^{4}$.

Com base nas percepções dos alunos, identifica-se a interveniência da gestão na humanização, presente de forma clara ou nas entrelinhas das experiências dos estudantes.

O trabalho interdisciplinar, a organização do processo de trabalho e a gestão pela qualidade são temas também identificados nos discursos dos alunos, mas nos limitamos aos aspectos da organização de trabalho por entender que esta contempla os outros temas em sua discussão.

A importância que se dá à gestão nesta pesquisa se refere a sua característica de determinante sobre o cotidiano das práticas de saúde, como ilustra a narrativa a seguir, atingindo o ensino médico e as práticas de atenção numa perspectiva humanizadora ou não na graduação:

"Era uma senhora que estava com uma insuficiência renal importante, só que ela não se encaixava nos critérios adotados pelo hospital para entrar em hemodiálise. E, por conta disso, mesmo não entrando nos critérios, ela estava com algum sintoma de insuficiência renal. Ela estava totalmente anasarcada, muito edemaciada, com dificuldades de respiração, porque ela estava retendo muito líquido no pulmão. E a gente pediu uma avaliação para tentar indicar hemodiálise. Só que a equipe que controla aquilo dizia: "Ela não tem indicação, não vai fazer hemodiálise, não vai fazer". Só que a senhora estava tendo repercussões por conta dessa atitude. Bom, até aí era um fato, a gente estava tentando contornar de outras formas, mas não estava conseguindo resultado. O fato é que um dia, durante uma visita, um assistente chegou e falou: "Por que ela não está conseguindo entrar no critério?"“ Porque um dos rins ainda tem uma pequena atividade", não sei quantos por cento, não vou me lembrar ao certo. E aí ele sugeriu que a gente aplicasse um medicamento, que terminasse, que destruísse esse pouco... dessa pouca atividade que ela tinha, porque aí ela conseguiria entrar no critério da nefrologia. Eu achei aquilo de uma... uma... sei lá... não sei nem como falar, mas uma loucura tão grande, entendeu, e aquilo para mim foi totalmente burocrático, desrespeitoso, foi um negócio grosseiro... Ele não sugeriu isso para a paciente. Na verdade, a gente não deixou. Mas eu achei... a visão que ele tinha da coisa era tão burocrática... tão superficial, que é um exemplo que me chamou muito a atenção, entendeu?"(aluno 2)

O trecho acima oferece elementos para diferentes discussões, porém dois pontos importantes são fortemente destacados: o aspecto econômico e a atitude do professor. Estes dois pontos dizem respeito à reflexão sobre as prioridades nos serviços de saúde, o que leva a questionar se os critérios de gestão estão acima dos aspectos do cuidado. Nota-se, nessa situação, que um protocolo de gestão de recursos se sobrepôs ao cuidado. Certamente, há que se considerar que tais protocolos visam a uma indicação técnica de alocação de recursos, que devem ser administrados tendo em vista benefícios individuais e coletivos. Também se coloca em questão se a atitude do professor corrompe a ética, pensada enquanto responsabilidade para com o outro ${ }^{22}$. Como organizadora da ação, a ética exige uma reflexão crítica sobre responsabilidades e valores para o bem coletivo e individual em cada situação.

O relato do aluno 2 apresenta uma situação que exige uma discussão ética, pois the é proposto causar um dano controlado ao paciente para encaixá-lo nos critérios de acesso a um recurso de saúde.

Quando se trata de priorizar recursos, os interesses econômicos, sociais, corporativos e outros são vinculados claramente à tomada de decisões, porém estas decisões também estão sujeitas a uma sociedade construída com valores morais. Os valores são fatores importantes no processo de escolha, impedindo que as decisões se baseiem apenas em fatos ${ }^{23}$.

A atitude do professor foi tomar decisões com base nos fatos, enquanto os alunos relacionaram a situação com possíveis valores envolvidos. O aluno diz que a visão do professor foi "burocrática", não houve uma reflexão acerca das possibilidades de ação ética frente àquele impasse.

A organização dos serviços e do espaço é destacada pelos alunos como algo fundamental para o exercício da humanização. Os alunos associam as práticas não humanizadas à falta de estrutura do ambiente, que deveria ser voltado ao cuidado. Quando se deparam com a precariedade de recursos para o seu trabalho - poucos leitos, poucos profissionais na equipe 
de saúde, recursos tecnológicos em menor quantidade do que o desejável, entre outros-, estes alunos também se defrontam com determinado modo de lidar e trabalhar nessas condições, que associam à falta de humanização:

\footnotetext{
"Aquela correria, um monte de pacientes, é comum... você passa por cima dos casos, as pessoas falam, a gente discute na frente do paciente, ele ouve a discussão nossa, ouve que está com uma doença e não sabe o que significa... sabe... todo mundo discutindo, o paciente lá angustiado, e a gente sem dar a mínima importância". (aluno 10)
}

A falta de estrutura física e de recursos humanos, a demanda maior que a oferta, o tempo limitado para a atenção ao paciente são justificativas apresentadas pelos alunos como fatores determinantes da falta de humanização nos serviços de saúde. Isto concorda com a literatura, segundo a qual, para alcançar bons resultados nos serviços de saúde, qualidade, eficiência, responsabilidade, cuidado, acolhimento e educação permanente são fundamentais, pois "humanizar a assistência é humanizar a produção dessa assistência"'24 (p. 13).

\section{Ensino médico}

As considerações acerca da categoria ensino médico têm como base as determinações das Diretrizes Curriculares Nacionais do Curso de Graduação em Medicina, o projeto pedagógico do curso de Medicina da Faculdade de Medicina da Universidade de São Paulo, os objetivos da Área de Humanidades e as ementas e planos de ensino de suas disciplinas no ensino de graduação. Com base nestes documentos, pode-se refletir sobre as falas dos estudantes em relação ao ensino na graduação da FMUSP.

A inserção das disciplinas de humanidades na grade curricular do ensino médico vem ocorrendo há algum tempo não somente no Brasil, mas também em outras partes do mundo. Contudo, frequentemente, os alunos as veem como desinteressantes e dispensáveis, em parte porque, embora fundamentais à boa prática médica, muitas vezes são abordadas de forma superficial nos currículos médicos ${ }^{4,10}$.

Um aspecto identificado no discurso dos alunos entrevistados é a abordagem da humanização no ensino, colocada em segundo plano na formação médica pelas disciplinas mais gerais, ainda que a humanização seja abordada nas disciplinas específicas da área de humanidades:

"[...] durante o curso médico, a gente tem alguns cursos que acabam englobando essa ação de humanização, mas são raras as vezes em que a gente consegue colocar em prática a humanização entre alguns temas". (aluno 5 )
Assim como a dificuldade de clarificação do conceito de humanização, a inserção das humanidades e sua abordagem na graduação parecem algo superficial e com pouca familiaridade aos alunos e professores. Apesar do reconhecimento da necessidade de fundamentação prática e teórica nos saberes humanísticos para que a integralidade do cuidado seja efetiva, as humanidades são desconsideradas do corpo da medicina ${ }^{16}$.

Esse desencontro da área de humanidades na formação médica apareceu como real na fala de alguns alunos. No entanto, alguns afirmaram que a área das humanidades era bem abordada durante o curso, considerando-a como uma realidade crescente.

$\mathrm{Na}$ fala dos alunos, as disciplinas de Pediatria, Clínica Médica e Ética Médica citariam mais diretamente temas das humanidades, enquanto Ginecologia, Dermatologia, Patologia e Radiologia se apresentariam como disciplinas menos envolvidas com a humanização. Segundo eles, haveria claro desinteresse pelo tema por parte dos professores e dos alunos, muito embora indiretamente apareça articulado a modelos de ser médico ("bom médico" ou "mau médico"). Os alunos relatam a importância das ações de seus professores para a compreensão da humanização, enquanto experiências positivas ou negativas relacionadas ao que consideram bons e maus exemplos de postura profissional.

\footnotetext{
“O professor da cirurgia lá no HU... o carinho que ele tem pelo que ele faz, dá para perceber que ele gosta, e isso ele transmite para todo mundo, para a equipe profissional, para os alunos, os residentes e principalmente para os pacientes. O jeito como ele trata os pacientes é admirável. É exemplo, eu acho isso muito importante. Agora, na maior parte são... como se diz... são pessoas normais assim..., não fazem mal, mas também não são pessoas que você queria como exemplo". (aluno 1)
}

Sobre o ensino da humanização, os alunos apontam a importância de articular teoria e prática:

\begin{abstract}
"[...] a faculdade está se esforçando para colocar a humanização no currículo médico... mas acho que falta a maturidade nossa e a experiência de saber colocar aquilo que a gente aprende na prática. Acho que isso é que está faltando. Não é apresentar novas matérias, novas disciplinas sobre humanização, mas saber correlacionar com algo que você teve de experiência. Acho isso importante". (aluno 5)
\end{abstract}

Ou seja, há necessidade de colocar a teoria a serviço da prática e não só inserir novas disciplinas desse campo. Esta 
necessidade observada pelos alunos é confirmada em outros estudos referentes ao tema, que mostram predominância da abordagem das humanidades de forma teórica e pouco ligada à prática em medicina ${ }^{10}$.

Segundo essa autora, os temas humanísticos ainda não são suficientemente integrados ao núcleo duro da formação médica. Entretanto, há iniciativas que buscam integrar temas humanísticos no ensino do cuidado em saúde de tal forma que a humanização faça sentido para os alunos.

\section{DISCUSSÃO}

Neste estudo acerca das percepções de alunos de Medicina quanto à humanização durante sua formação, percebe-se que há pouca familiaridade com a temática, o que transparece na imprecisão e insegurança de suas falas.

Essa distância do tema apareceu na fala de todos os alunos entrevistados, em uns mais, em outros menos. Entretanto, ao buscarem em suas experiências a presença ou ausência da humanização, acabaram apresentando elementos que compõem este campo de estudo e que são fundamentais para o exercício da medicina.

Humanização, a partir dos relatos dos alunos, seria o compromisso e a valorização das pessoas nas ações de saúde, o que está em conformidade com os princípios da humanização na $\mathrm{PNH}^{7}$. A aproximação entre a humanização e a relação médico-paciente está fortemente presente nos discursos dos alunos. Tais relações são fontes ricas de exemplos que ilustram a compreensão da humanização. De acordo com a literatura, nos serviços de saúde, uma das formas como a humanização aparece é na busca de melhorias na relação médico-paciente ${ }^{5}$. Ao retomar a ideia de que a relação médico-paciente é um elemento-chave na atenção à saúde ${ }^{8}$, a humanização aparece como um princípio que aumenta a qualidade relacional, enfatizando o aspecto comunicacional dialógico.

A empatia, embora possa ser compreendida de diferentes formas, segundo a visão de diferentes autores, destaca-se como uma habilidade comunicacional que permite a compreensão do outro e a comunicação dessa compreensão ${ }^{21,18}$. Segundo os alunos, a abordagem da humanização no ensino médico estaria em segundo plano nas disciplinas mais gerais, e mais presente nas disciplinas de humanidades. A dificuldade de integração das humanidades à medicina foi ressaltada pelos alunos, concordando com a literatura. Apesar do reconhecimento da necessidade dos saberes humanísticos para a integralidade do cuidado, o desencontro da área de humanidades na formação médica ainda é real ${ }^{16}$.

Nesse sentido, apontam a importância de inserir a humanização nos cenários de ensino de prática médica, efetivamen- te, como parte integrante de suas ações, como modo de ser médico dos professores e como parte da cultura institucional.

\section{REFERÊNCIAS}

1. Heckert ALC, Passos E, Barros MEB. Um seminário dispositivo: a humanização do Sistema Único de Saúde (SUS) em debate. Interface (Botucatu) 2009;13 (supl 1) [Capturado em: 20 de mai. 2011];493-502. Disponível em: http:/ / www.scielo.br/scielo.php?script=sci_arttext\&pid=S1414$-32832009000500002 \& \operatorname{lng}=\mathrm{en} \& n r m=$ iso $>$.

2. Deslandes SF, Mitre RMA. Processo comunicativo e humanização em saúde. Interface (Botucatu) 2009;13 (supl1) [Capturado em: 27 set. 2012]; 641-649. Disponível em: <http:/ / www.scielo.br/scielo.php?script=sci_arttext\&pid=S1414-32832009000500015\&lng=pt\&nrm=iso $>$.

3. Benevides R, Passos E. A humanização como dimensão pública das políticas de saúde.Ciência e Saúde Coletiva 2005;10(3) [capturado em: 29 abr. 2011]; 561-571; Disponível em:<http://www.scielo.br/scielo.php?script=sci_ arttext\&pid=S1413-81232005000300014\&lng=pt\&nrm=iso $>$.

4. Rios IC. Caminhos da Humanização - Reflexão e prática. São Paulo: Áurea; 2009.

5. Puccini PT, Cecilio LCO. A humanização dos serviços e o direito à saúde. Cad. Saúde Pública 2004; 20(5); [Capturado em: 29 set. 2011];1342-1353, 2004. Disponível em: <http:/ / www.scielo.br/scielo.php?script=sci_arttext\&pid=S0102$-311 X 2004000500029 \& \operatorname{lng}=$ pt\&nrm=iso $>$.

6. Tornquist CS. Armadilhas da Nova Era: natureza e maternidade no ideário da humanização do parto. Ver Estud Fem. 2002; 10(2) [Capturado em: 21 Mai 2011]; 483-492. Disponível em: <http://www.scielo.br/scielo. php?script=sci_arttext\&pid=S0104-026X2002000200016\&1 $\mathrm{ng}=\mathrm{pt} \& \mathrm{nrm}=\mathrm{iso}>$.

7. Brasil. Ministério da Saúde. Humanizasus: Política Nacional de Humanização do Ministério da Saúde. Brasília, DF: MS; 2010

8. Caprara A, Franco ALSA. A Relação paciente-médico: para uma humanização da prática médica.Cad. Saúde Pública. 1999; 15(3) [Capturado em: 06 jul. 2013]; 647-654. Disponível em:<http:/ /www.scielo.br/scielo.php?script=sci_ar ttext\&pid=S0102311X1999000300023\&lng=pt\&nrm=iso $>$.

9. Ayres JRCM. O cuidado, os modos de ser (do) humano e as práticas de saúde. Saude soc.2004;13(3)[Capturado em: 27 set. 2011];16-29. Disponível em: <http://www. scielo.br/scielo.php?script=sci_arttext\&pid=S0104$-12902004000300003 \& \operatorname{lng}=$ pt\&nrm=iso $>$.

10. Rios IC,Junior AL, Kaufman A, Vieira JE, Scanavino MT, Oliveira RA. A integração das disciplinas de humanidades 
médicas na Faculdade de Medicina da USP: um caminho para o ensino. Rev Bras Educ Med. 2008; 32(1) [Capturado em: 12 mar. 2011];112-121. Disponível em:<http:// www.scielo.br/scielo.php?script=sci_arttext\&pid=S0100$-55022008000100015 \& \operatorname{lng}=$ pt\&nrm=iso $>$.

11. Pereira OP, Almeida TMC. A formação médica segundo uma pedagogia de resistência. Interface - Revista de Comunicação e Educação. 2005; 9(16) [Capturado em: 15 mar. 2009]; 69-79. Disponível em:<http://www. scielo.br/scielo.php?script=sci_arttext\&pid=S1414$-32832005000100006 \& \operatorname{lng}=$ pt\&nrm=iso $>$.

12. Brasil. Ministério da Educação. Conselho Nacional de Educação. Resolução CNE/CES no. 4, de 7 de novembro de 2001. Diretrizes curriculares nacionais do curso de graduação em Medicina. Disponível em http://portal.mec.gov. br/cne/arquivos/pdf/CES04.pdf.Acesso em: 09 mai 2011.

13. Minayo MCS. O desafio do conhecimento. Pesquisa qualitativa em saúde. São Paulo;Rio de Janeiro: Hucitec; Abrasco; 1994.

14. Schraiber LB. Pesquisa qualitativa em saúde: reflexões metodológicas do relato oral e produção de narrativas em estudo sobre a profissão médica. Rev. Saúde Pública 1995; 29(1) [Capturado em 19 jan. 2012]; 63-74. Disponível em:<http:/ / www.scielo.br/scielo.php?script=sci_arttext\&pid=S0034$-89101995000100010 \& \operatorname{lng}=$ pt\&nrm $=$ iso $>$.

15. Minayo MCS, Deslandes SF, Gomes R. Pesquisa Social: Teoria, método e criatividade. Petrópolis: Vozes; 2012.

16. Rios IC. Subjetividade Contemporânea na Educação Médica: A formação Humanística em Medicina.São Paulo; 2010. Doutorado [Tese] — Faculdade de Medicina da Universidade de São Paulo.

17. Rios IC. Comunicação em medicina. Revista de Medicina 2012; [Capturado em: 15 Mai. 2014]; 159-162. Disponível em: <http:/ / www.revistas.usp.br/revistadc/article/ view / 58977/61963>

18. Falcone EMO, Ferreira MC, Luz RCM, Fernandes CS, Faria CA, D’Augustin JF, et al. Inventário de Empatia (I.E.): desenvolvimento e validação de uma medida brasileira. Aval. psicol. 2008; 7(3) [Capturado em: 15 fev. 2012]; 321-334. Disponível em:<http://pepsic. bvsalud.org/scielo.php?script=sci_arttext\&pid=S1677$-04712008000300006 \& \operatorname{lng}=$ pt\&nrm $=$ iso $>$.
19. Rider EA, Keefer CH. Communication skills competencies: definitions anda teaching toolbox. Medical Education 2006; 40: 624-629.

20. Makoul G. A Guide for Instructors and Learners: the Segue Framework for Teaching and Assessing Communication Skills. Fortaleza; 2005.

21. Koller SH,Camino C, Ribeiro J. Adaptação e validação interna de duas escalas de empatia para uso no Brasil. Estudos de Psicologia. 2001; 18: 43-53.

22. Lévinas E. Entre nós - ensaios sobre a alteridade. Petrópolis: Editora Vozes; 2009.

23. Oselka G (coord.). Bioética Clínica: reflexões e discussões sobre casos selecionados. 2.ed. São Paulo: Conselho Regional de Medicina do Estado de São Paulo. Centro de Bioética; 2009.

24. Deslandes SF. Análise do discurso oficial sobre a humanização da assistência hospitalar. Ciência e saúde coletiva. 2004; 9(1) [Capturado em: 15 março 2009];7-14. Disponível em: <http://www.scielo.br/scielo.php?script=sci arttext\&pid=S1413-81232004000100002\&lng=en\&nrm=iso >

\section{CONTRIBUIÇÃO DOS AUTORES}

As autoras desenharam o modelo do artigo e escreveram-no conjuntamente. Coube à primeira autora a revisão e edição final do manuscrito.

\section{CONFLITO DE INTERESSES}

As autoras declaram não haver conflitos de interesses.

\section{ENDEREÇO PARA CORRESPONDÊNCIA}

Izabel Cristina Rios

Núcleo Técnico e Científico de Humanização do Hospital das Clínicas da Faculdade de Medicina da Universidade de São Paulo.

R. Doutor Ovídio Pires de Campos, 225 - 6º andar

Cerqueira César - São Paulo

CEP: 05403-010 SP

E-mail: izarios@usp.br 